\title{
Stigma and labour market outcomes: sex work and domestic work in India
}

\section{Article}

Accepted Version

Hui, N. and Kambhampati, U. S. (2020) Stigma and labour market outcomes: sex work and domestic work in India. Journal of Development Studies, 56 (1). pp. 112-128. ISSN 1743-9140 doi:

https://doi.org/10.1080/00220388.2018.1564906 Available at https://centaur.reading.ac.uk/81070/

It is advisable to refer to the publisher's version if you intend to cite from the work. See Guidance on citing.

To link to this article DOI: http://dx.doi.org/10.1080/00220388.2018.1564906

Publisher: Taylor and Francis

All outputs in CentAUR are protected by Intellectual Property Rights law, including copyright law. Copyright and IPR is retained by the creators or other copyright holders. Terms and conditions for use of this material are defined in the End User Agreement.

\section{www.reading.ac.uk/centaur}

\section{CentAUR}

Central Archive at the University of Reading 
Reading's research outputs online 


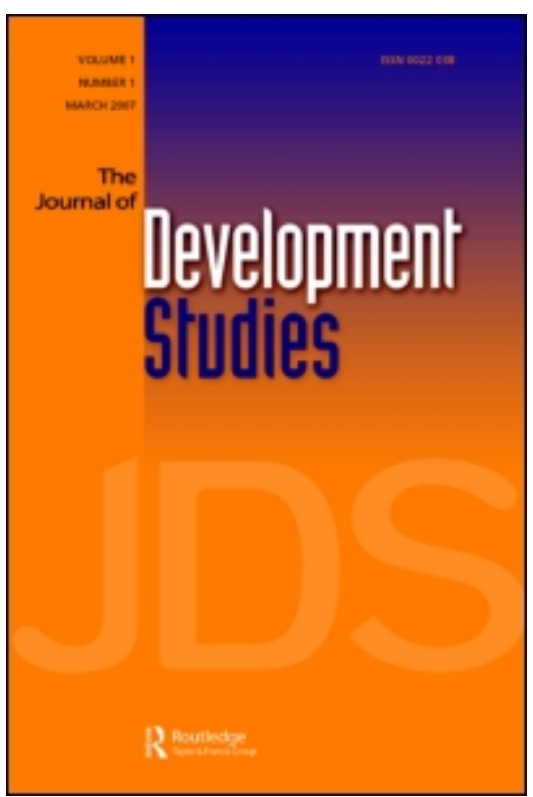

Stigma and Labour Market outcomes: Sex work and domestic work in India

\begin{tabular}{|r|l|}
\hline Journal: & Journal of Development Studies \\
\hline Manuscript ID & FJDS-2017-Aug-0106.R2 \\
\hline Manuscript Type: & Original Manuscripts \\
\hline Keywords: & Sex work, domestic work, stigma, earnings premium, abuse \\
\hline \multicolumn{2}{|l}{} \\
\end{tabular}

\section{SCHOLARONE' \\ Manuscripts}




\section{Stigma and Labour Market outcomes: Sex work and domestic work in India}

Neha Hui* and Uma S. Kambhampatib

${ }^{a}$ Department of Economics, University of Reading, Reading, United Kingdom; ${ }^{b}$ Department of Economics, University of Reading, Reading, United Kingdom

n.hui@reading.ac.uk 


\title{
Stigma and Labour Market outcomes: Sex work and domestic work in India
}

\begin{abstract}
In this paper, we examine whether the earnings of sex workers in India are significantly different from those in domestic work, a trade that is also gendered in nature and can be done with similarly low levels of training and education. We analyse this using data collected during fieldwork in the cities of Kolkata and Delhi in India. Our results confirm that there is a significant difference in wages between the two groups of workers. We consider the extent to which the stigma attached to sexwork contributes to the higher wages in this occupation relative to domestic work. To do this, we control for endogeneity caused by selection on unobservables. We find that stigma is a significant contributory factor to the wage differential. We also preliminarily consider an alternate explanation that of violence in the trade. We find that the experience of violence in the trade does not affect the take home earnings of the individuals.
\end{abstract}

Keywords: sex work; domestic work; stigma; earnings premium abuse

\section{Introduction}

One recurring issue in the economics literature on sex work relates to the high earnings in sex work relative to other occupations that require similar amounts of skill or training. The literature provides three main explanations for this high earnings puzzle: the opportunity cost of foregoing marriage (Edlund and Korn, 2000), compensation for the stigma of being associated with the trade (Della Giusta et al., 2008), and the risks involved in the trade (Arunachalam and Shah, 2008). It is, of course, likely that having to forego marriage or being the victim of violence themselves relate to the stigma attached the trade. Since stigma could be the factor underlying both the marriage and violence explanations, we empirically explore the stigma explanation in this paper in the context of two gendered occupations - sex work and domestic work - in two cities in India. To do this, we analyse the selection of women into two trades - sex work and domestic work - and consider the factors that affect the earnings in these trades. Both sex work and domestic work constitute workers of very similar profile in India (in terms of age, level of education, socio-economic background and gender). The main difference between the two groups of workers is that sex workers are stigmatised because of their occupation while domestic 
workers are not. Our analysis is based on fieldwork conducted by one of the authors in two large Indian metropolises - Kolkata and New Delhi - in summer 2013. We analyse this data, taking into account potential endogeneity in the estimation. We find that the characteristics of the worker alone cannot explain the difference in the earnings between the two groups. We argue that the unexplained factor that results in the difference in earnings may be the stigma attached to the trade.

In India, sex workers and domestic workers are predominantly female, uneducated and unskilled (Sahni and Shankar, 2011), with the work being done in both cases being considered to be innately feminine. The literature also suggests that the workers in these two sectors are similar in terms of age of entry (Sen and Sengupta, 2012), level of education and formal training as well as the labour market options open to them (Wadhawan, 2013). Accounts from women in sex work indicate that many women enter sex work after having provided unpaid sexual services to employers in paid domestic work (Durbar Mahila Samanavaya Committee, 2006; Jameela, 2009). Thus, the existing literature confirms that low paid sex workers and domestic workers are comparable groups in terms of the occupational traits and demographic characteristics of the individuals involved.

Our paper makes the following contributions to the literature. First, by comparing two groups of women (with similar characteristics) in different types of work, we can identify the extent to which pay differentials stem from worker characteristics as opposed to the characteristics of the occupation. In doing so, we add to the literature on sex work as well as gendered labour markets. Second, we rely on data collected specifically for this purpose through fieldwork in India. It is almost impossible to study the sex work industry using secondary data sources. While the Indian National Sample Survey (Education and Employment Schedules), for instance, does have a category (97) which is meant to include prostitutes, they are placed in this group together with beggars and 'other'. It is therefore impossible to separate the sex workers from others. It also has 
many missing observations. Primary data of the kind we have collected not only targets sex workers and domestic workers directly but also enables us to ask specific questions about their work and their agency as well as their constraints and motivations. This gives us first-hand insight into these labour markets and helps with our analysis. Third, we make methodological progress by allowing for endogeneity. Many estimates of wage returns are confounded by sample selection as well as endogeneity bias because women with certain characteristics might opt to be sex workers or domestic workers and these characteristics might also influence their wages. In this paper, we correct for such endogeneity and in the process obtain causal estimates of wages that enable us to determine whether the difference in wages is caused by stigma. We use two measures of stigma - in the first we assume that being a sex worker implies stigma (all sex workers are stigmatised and they are compared with non-stigmatised domestic workers) and in the second, stigma is determined by whether the family accepts the work being done by the individual.

The rest of the paper is structured as follows: in the next section we briefly look at the price premium on sex work and place our contribution in the current literature. In the following section 3 we discuss the background of this research, especially relating to the similarities and differences in the two trades. Section 4 describes the process of data collection including its limitations in terms of representativeness of the populations. In section 5 we discuss the empirical methods used, including the problem of selection bias and endogeneity. We discuss the results in section 6 and conclude in section 7.

\section{Literature Review}

As mentioned earlier, three explanations have been put forward in the literature to explain the wage premium in sex work - the cost of foregoing marriage, the stigma attached to the work and the occupational hazards of employment in this sector. The wage premium debate for sex work 
was initiated by Edlund and Korn (2002) who argued that the reason that sex work was well paid in spite of being low skill, labour intensive and female was that sex workers were paid a premium for foregoing marriage. The authors argue that a woman cannot be both a sex worker and a wife. This together with the fact that marriage is often a source of income for women implies that sex work must pay more than what marriage would offer the woman. For Edlund and Korn, sex work is defined in terms of the client's demand for non-reproductive sex (as against reproductive sex in a marriage). They therefore argue that the significant difference between sex work and marriage for the authors isn't in the commercial nature of the sexual services- women in marriage, the authors argue, also provide paid sexual services - but in the access to paternity to children as a consequence of the sexual interaction. While Edlund and Korn recognise social stigma and reputation costs for the sex worker, both of which are consistent with their model outcomes, the mechanism for tradeoff between sex work and marriage isn't the stigma that might make the sex worker's access to the marriage market limited. Instead, it is that the higher wages are a compensation for the fact that children born to women in this trade have no access to paternity.

The marriage market argument put forward by Edlund and Korn has however been empirically refuted by various authors including Arunachalam and Shah (2008) for Ecuador and Mexico, Robinson and Yeh (2008) for Western Kenya. The marriage market argument would also not hold in case of erotic services that do not involve the possibility of reproduction including nonvaginal sex and pornography. It would also not hold in cases where sex workers have easy access to non-barrier contraception including contraceptive pills. The argument would also not be applicable for the premium earned by male sex workers. It is to be noted here that the data in this paper also doesn't concur with Edlund and Korn's argument with 44.5 percent of the sex workers in the sample reporting to being married or with partner. 
The two main alternative arguments put forward in the literature are those relating to the risk premium being paid in the trade or the stigma cost of being associated with it. Arunachalam and Shah (2008) used the risk premium argument for earnings premium between sex work and other trades. They argued that sex work draws a hazard pay, similar to other risky professions like policework. In addition, various authors (Arunachalam and Shah, 2011; Rao et al, 2003; Robinson and Yeh, 2011) have argued that, within the trade, there is a further premium attached to risky sex and to sex workers who engage in unprotected sex. The risk compensation theory argues that individuals have differentiated propensity for taking risks, and the propensity is influenced by the rewards of risk taking (Adams, 1995). Thus, for a sex worker who makes an occupational choice of entering the trade, her decision is an outcome of weighing her perceptions of risk (given her actual or perceived experiences of loss) against the compensation received in the trade, which influences her propensity to take the risk in the first place. Much of this literature focuses on the health risks associated with unprotected sex, despite vulnerability to violence being an intrinsic part of the occupation. We are interested in the vulnerability to violence as the risk due to unprotected sex is a risk both to the sex worker and the client, while the vulnerability to abuse is a risk that disproportionately affects the sex worker and not the client. There is ample evidence from India and the rest of the world that vulnerability to violence is an intrinsic aspect of sex work (Sanders 2004; Brent and Hausbeck 2005; Beattie et al., 2010; Sarkar et al., 2008; Argento et al., 2011). However, it is also clear (Deering et al., 2004; Blanchard et al., 2005) that this risk is increased by the stigma attached to the occupation. This implies that while society at large is more sympathetic to violence faced by domestic workers, the sex worker is deemed to be a 'bad' woman and hence 'deserving' of the violence she faces. Hence accessing legal aid or health care in case of abuse is more difficult for the sex worker (Lazarus et al., 2013), making sex work more risky in comparison to domestic work. Of course, 
there are risks involved in domestic work too which have been documented in the literature (Chuang, 2010; Huang and Yeoh, 2007; Nilsson et al., 1985; Dinat and Peredy, 2007).

This brings us to the third main argument for the earnings premium in sex work- the stigma premium. There is no disagreement in the literature that sex work is stigmatised (Scambler, 2007; Biradavolu et al., 2012; Cornish, 2006; Benoit et al., 2006; Wong et al., 2011 among others). There is also considerable agreement that this stigma perpetuates the other explanations (those relating to marriage as well as violence). We will look at it therefore in a little more detail. Scambler argues that the shame or the stigma that is attached to the trade is a consequence of the moral standpoint on sex and sexuality and is almost exclusively attached to the female supplying sexual services. For Scambler, shame or stigma in sex work arises because society draws a binary between the 'whore'/bad woman and 'Madonna/good woman' and the Madonna's existence is defined in terms of the whore's deviance. A sex worker is stigmatised as an individual because of the deviance of her trade from socially acceptable forms of work and the digression of her behaviour from socially sanctioned norms regarding woman's behaviour around sexuality (Wong et al 2011).

Ashforth and Kreiner (1999) classified "dirty work" to be that which contains some sort of "taint". They characterise "taint" as physical, which includes contact with garbage, death, effluence and noxious conditions et cetera; social, which includes regular contact with stigmatised others, servile relationship and moral, which includes 'sinful' or dubious virtue, deceptive, intrusive, and confrontational methods. Their classification of 'tainted' occupations therefore includes a variety of occupations ranging from dentists to exotic dancers to police interrogators. The argument put forward is that dirty work is not viewed as trivial or unimportant work to society, but is viewed as distasteful, if not disgusting. The work is necessary but polluting. Ashforth and Kreiner argued in 2014 that the three classes of occupation: i.e. those characterised by physical, social or moral taint are all considered dirty, but are perceived 
differently by society. The occupations with physical or social 'taint' or 'dirt', which would include domestic work, are considered 'necessary evil' while occupations with moral 'dirt', like sex work, are considered more evil than necessary. Thus, by their definition while both the trades involve 'dirt', the 'dirt' associated with sex work is less acceptable by society and therefore stigmatised more.

The stigma compensation model put forward by Della Giusta et al. (2008), formally introduces reputation effects for both the sex worker and the client. The authors show, through supply/demand analysis, that the equilibrium price is affected by the reputation of both the client and the sex worker. In Della Giusta et al.'s model, the possibility of reputation loss of the client (as a consequence of the transaction) has a negative effect on the equilibrium price of transactions while the possibility of reputation loss of the sex worker has a positive effect on price.

In this paper we will primarily focus on the stigma compensation argument, though we will also look into the risk compensation argument. We privilege this argument over the other two because we see stigma as the cause underlying both risk in the trade as well as disadvantage in the marriage market. For example, Niang et al. (2003) have argued that stigma in the trade results in vulnerability of providers of sexual services to abuse and exploitative conditions. Similarly, Peracca et al. (1998) found that in Thailand, where the stigma attached to sex work is comparatively mild, the general public is more open to the idea that sex workers can marry. Even though the authors who put forward the marriage and the risk premium arguments did not consider stigma as the mechanism behind the earnings premium, they all acknowledged the presence of stigma.

Scambler (2007) stipulate two types of stigmas that the individual faces - felt and enacted stigma. Felt stigma is the shame associated simply with belonging to the stigmatised group and 
the fear of facing enacted stigma. Enacted stigma, on the other hand, manifests in episodes of discrimination against people with the stigmatised condition because of their social or cultural unacceptability. Thus, the sex worker experiences felt stigma as soon as she enters the trade because she feels the shame of belonging to a trade that is socially unacceptable or because she fears discrimination as a consequence of being in the trade. Additionally, she also encounters enacted stigma in the form of discriminations as soon as her occupation is known to others.

Based on this categorisation of stigma, we develop two ways in which stigma can be incorporated in our analysis. The individual experiences felt stigma as she enters the trade which implies that her reservation price in the trade will be higher than for other occupations, therefore implying higher earnings. Thus, a counterfactual analysis (in terms of what would have been the outcome had the sex worker been in some other occupation, say domestic work) should be able to capture the effect of this felt stigma on her earnings. We capture felt stigma by including the status of the individual as a sex worker (as opposed to domestic worker) in the model. We note here that there may be concerns of endogeneity, which we address using instruments mentioned in section 4. Second, to capture enacted stigma, we consider whether individuals were stigmatised by their own families because of their entry into their trade. We use a variable constructed from the self-reported experience of whether the individual's family accept their work or would have accepted their work had they known. This measures the discrimination she might expect to face or the enacted stigma she encounters, starting from home. The construction of the variables is discussed in section 3 .

\section{Data and Summary Statistics}

In this paper we attempt to understand the selection of otherwise similar individuals into two trades - sex work and domestic work - and what factors affect labour market outcomes in terms of the earnings of the worker. Using primary data for sex workers and domestic workers in two 
cities in India, we ask the following research questions: First, is there any systematic difference between the earnings of workers in the two trades given that the formal education/training requirements are low in both trades? Second, can the higher earnings in sex work be understood as a compensation for the stigma associated with the trade? Alternatively, can the higher earnings also be explained by the risk of abuse in the trade?

To analyse these questions, we use data from a primary field survey of sex workers and domestic workers in two metropolitan centres in India - Delhi NCR (National Capital Region) and Kolkata (previously known as Calcutta) - undertaken by one of the authors. The survey was undertaken in July-August 2013. For the sex workers in Kolkata, we targeted 4 red-light areas of South Kolkata - Kalighat, Chetla, Khiddirpur and Rambagan - and 3 red-light areas in North Kolkata (Rabindra Sarani, Set Bagan and SonaGacchi). The first set of sex workers contacted in Kolkata were through the collective of sex workers called Durbar Mahila Samanwaya Committee (henceforth called Durbar) ${ }^{i}$. The subsequent participants were identified by this first set of sex workers ${ }^{\mathrm{ii}}$. The officials from Durbar also put us in touch with a non government organisation working with Delhi based sex workers called Savera which helped us identify sex workers in Delhi. In Delhi, our survey areas were Rohini District in West Delhi and GB Road in East Delhi. Our domestic worker sample was chosen from the slum areas in the vicinity of the red-light areas. This allowed us to concentrate on women with demographic and socio-economic profiles similar to those of our sex worker sample. While sex workers for our survey were identified with the help of NGOs, for domestic workers, we identified employers of domestic workers who gave us contacts of their employees and also identified domestic workers living in a particular area. In both cases, the workers then introduced us to other workers.

Not surprisingly, snowball sampling of this kind, while dictated by the nature of the work being considered, is limited in terms of the representativeness of the resultant sample. In particular, for 
sex workers we are more likely to have interviewed workers with contacts with the NGO. These workers are likely to be either those with significant problems being dealt with by the NGO or those who are more pro-active in the industry and therefore have become involved with the NGO. Our sample may therefore be biased. Similarly, for domestic workers, our sample might be biased towards those who had good relations with their employers. However, given that sex workers in particular are hidden and hard to reach, this survey method is often the only feasible method of data collection that can ensure both the privacy and safety of the respondent as well as the safety of the researcher (Goodman, 1961; Noy, 2008). Consequently many studies on sex work collect data in this manner (Gerassi et al., 2016; Boels and Verhage, 2016; Kramar, 2004) ${ }^{\mathrm{iii}}$. Our dataset constitutes 521 individuals: 274 are live out ${ }^{\mathrm{iv}}$ domestic workers and 247 are lower end brothel based sex workers.

Conservative estimates suggest that there are between 2 and 3 million women employed in the sex industry in India and anything between 2.5 and 7 million women employed in domestic work $^{\mathrm{v}}$ Both these informal sector occupations have similarities that are hard to miss. Both have a strong gender element, insofar as one, workers employed in these trades are usually women the world over, and two, these two services have been traditionally deemed as 'women's work'. Furthermore, these two trades are similar in terms of their formal skill and training requirements. Low paid domestic work and sex work require very little or no formal education or training. The legal status of both these jobs is characterised by obscurities and is hard to interpret and implement for the benefit of employees (Sharma and Kunduri, 2015; EPW editorial, 2014). Together with the lack of regulatory framework, it also implies vulnerability to abuse for women in both the trades which has been documented by numerous authors (Huang and Yeoh, 2007; Sarkar et al., 2008; Murty, 2009).

Brothel based sex workers have a place of residence (often the brothel, though sometimes sex workers work in the brothel but reside elsewhere in the city with their families) which 
differentiates them from street-based sex workers, who are often homeless. Part-time domestic workers also have a place of residence though this is different from their workplace. We note that we have restricted ourselves to individuals who are currently not bonded to any brothel (even though they may have been bonded in the past). Consequently, we are considering individual sex workers who have some degree of 'choice' regarding involvement in the trade. Similarly, the advantage of considering 'live-out' domestic workers is that they are likely to have more mobility and freedom to negotiate, which may not always be the case for live-in domestic workers, who have very little freedom to manoeuvre and negotiate.

Summary statistics (Table 1) confirm that the two samples are similar (in terms of socioeconomic background and levels of education). While our sex worker sample is younger on average (at 32 years) than our domestic worker sample (37 years), the age of entry of women into both the professions is remarkably similar at an average of 21.4 years for sex workers and 20.4 for domestic workers. While there are no national representative studies for us to be able to compare the representativeness of our sample, Saggurti et al. (2011) in their study of 5498 sex workers from 22 districts in India find the age of entry into sex work in their sample to be 24.1 years, which is older than our sample average, indicating that our sample doesn't overstate the age of entry in sex work. In terms of educational attainment, in our sample 68 percent and 70 percent of sex workers and domestic workers respectively have never been enrolled in school indicating that most individuals in both the occupations have little or no formal education. Having said this, the proportion of women who have finished school or higher education amongst sex workers is 2.8 percent while that of domestic workers is 0.3 percent.

Both groups have a higher than national average proportion of Scheduled Caste women (29 percent for sex workers and 35 percent for domestic workers) in comparison to 16.6 percent of scheduled castes in the national population ${ }^{\mathrm{vi}}$. This is confirmed in the literature which suggests that sex workers and domestic workers are more likely to be of the 'lower' castes (Basu et al. 
2004, Halli et al. 2006, Raghuram, 2001) and the sex work sample has higher than national average proportion of non-Hindu (mostly Muslim) individuals (at 27.53 percent), in comparison to 5.83 percent for domestic workers in this sample and 14.2 percent for the country as a whole). The family background of the two groups also demonstrates similarities. Approximately 24 percent of sex workers and 26 percent of domestic workers in our sample were raised in female headed households and on average they were brought up in large families with 2 male and 3 female siblings. Surprisingly, about 44 percent of sex workers and 40 percent of domestic workers grew up in households who owned the house that they lived in.

There are some differences between the two groups. First, while 31 percent of the domestic workers came from families which owned land, only 7 percent of the sex workers' families did so. Thus, sex workers seem to belong to land-poor households relative to domestic workers. Second, there is a significant difference in terms of experience of past violence. On average 39.34 percent of sex workers have faced physical, verbal or sexual abuse in their families before joining the trade and almost 30 percent faced violence in their previous occupation ${ }^{\text {vii. In }}$ comparison to this, only 1.42 percent of women in domestic work faced abuse in their previous occupations though 19.34 percent faced violence in their families We expect this to be a determining factor in the selection of individuals in the trade and we will exploit this difference in our estimation in the next section.

As we discussed before, the other difference between the two groups is regarding the stigma that the individual faces regarding their work. In the questionnaire survey the individuals were asked 'whether their family knew and accepted their trade' to which the possible responses were strongly disagree, disagree, neutral, agree, strongly agree. We create a binary variable 'stigma_family' that takes value 0 if the individual's response to the question was 'agree' or 'strongly agree', and 1 otherwise ${ }^{\text {viii }}$. Thus, the variable stigma_family measures whether or not 
the individual is stigmatised for her trade by her family. While for the domestic workers 93.66 percent of the individuals reported that their families knew and accepted their trade, for sex workers this was only 25.62 percent.

(Table 1 here)

Empirical Methodology: Identification, Endogeneity and Selection on Unobservables

We estimate the effect of occupational stigma on earnings outcomes using ordinary least squares regression and instrumental variables regression. As mentioned before we conceptualize stigma in two ways. First, we categorise being a sex worker as equivalent to being stigmatised because sex workers will face both enacted and felt stigma. Second, we use a self- reported variable capturing acceptance by the family of the individual. We therefore estimate two separate models, one in which we assume that being a sex worker (as opposed to a domestic worker) automatically implies stigma and a second in which the stigma is more directly included in the model. We begin by regressing our dependent variable 'log of hourly earnings' on 'sex work' (which takes value 1 if the individual is a sex worker and 0 if she is a domestic worker):

$$
y_{i}=\beta_{i} * \operatorname{sex} w o r k+\boldsymbol{\delta}_{\boldsymbol{i}} * \boldsymbol{x}_{\boldsymbol{i}}+\epsilon_{i}
$$

Where $y_{i}$ is the log of hourly earnings, $\beta_{i}$ is the coefficient of estimation for the variable sex work, $\boldsymbol{x}_{\boldsymbol{i}}$ is the vector of exogenous covariates which includes age, square of age, level of education, whether family of the individual is in the industry, whether the individual is high caste Hindu, location (whether the individual is based in Delhi) and hours worked.

In this estimation, we might expect $\beta_{i}$ to be biased because variables like personality traits or preferences that may influence entry into sex work as opposed to domestic work are omitted from the model. These traits may, for instance, be risk preferences or even time horizons. Individuals with stronger risk preferences are more likely to choose sex work as might those 
with shorter time horizons. The problem with these omitted variables is that they are likely to influence both the choice of sector to work in as well as incomes earned in these sectors. To correct for this endogeneity, we use an instrumental variables method where the sex work dummy is treated as endogenous and is explicitly modelled in Stage 1 and the predicted values from this stage are used in the second stage. To ensure that the relationship is identified, we need an instrument which is significantly correlated with the sex worker dummy but is also uncorrelated with the error term in the outcome equation (log of hourly earnings). The variable we include as an instrument in the first stage equation is whether or not the individual faced violence before joining the trade in their past occupation or in their families while growing up. We expect past abuse to influence the individual's choice of activity because it will affect their self-esteem as well as their aspirations, and this could influence whether or not the individual becomes a sex worker. To the extent that perception of self and aspirations affect the individual's earnings, it would be via occupational choice rather than directly. Our data has two variables that measure past violence- whether the individual faced violence in their family (before joining the trade) and whether the individual faced violence in their past occupation ${ }^{\text {ix }}$. We include both these as instruments. Summary statistics of these two variables are given in Table 1. It is to be noted that these variables have negligible correlation (coefficients of -0.0573 and -0.0082 , both insignificant) with our dependent variable, the log of earnings, leading us to conclude provisionally that the earnings premium of sex workers is not related to past violence. Our second way of conceptualising stigma is in terms of whether or not the individual's family accepts the individual's trade. We use the variable stigma family as described in the section above as the main covariate here. Our baseline OLS model here has dependent variable 'log of hourly earnings' and our main covariate is 'family accepts':

$$
y_{i}=\beta_{i} * \text { stigma_family }+\boldsymbol{\delta}_{\boldsymbol{i}} * \boldsymbol{x}_{\boldsymbol{i}}+\epsilon_{i}
$$


Like in the case of the earlier model, we cannot expect stigma_family to be exogenous. For example, there may be a problem of reverse causality. The family of the individual may be more accepting of their occupation if they earn high income. In this case, we will instrument this variable using past violence in the family. The acceptance of the family of the individual's trade may be correlated to whether or not the individual faced violence in the family. However, since there is no reason for violence in the past occupation to be related to the family's acceptance, we will drop this variable as an instrument.

\section{Alternative Explanation}

As discussed above, it is possible that the wage difference between sex workers and domestic workers can be explained as a premium for the vulnerability to abuse in the trade. We are interested to see if the experience of violence has any effect on the log of earnings of the individual involved. Since the nature of violence is different in the two trades we concentrate on the subsection of our sample only constituting of sex workers. To consider the effect of experience of abuse on the log of earnings, we regress our dependent variable 'log of hourly earnings' on the covariate abused in the trade (which takes value 1 if yes, 0 otherwise):

$$
y_{i}=\beta_{i} * \text { abuse in trade }+\boldsymbol{\delta}_{\boldsymbol{i}} * \boldsymbol{x}_{\boldsymbol{i}}+\epsilon_{i}
$$

We note that the covariate here is abuse in the trade. This is different from the instrumental variables used in Stage 1 which relate to past abuse faced by the individual before joining the trade. The problem of endogeneity persists even in this case as there may be unobservable factors that affect both the experience of violence in the trade as well as earnings from the trade. These may include the individual's risk aversion. An individual who is averse to taking risk may experience both lower levels of violence in the trade, as well as lower earnings. We will continue to use instrumental variable regression to get around this problem. The correlation between past abuse and current abuse, in the context of sex work, has been noted in the literature (Silbert and 
Pines, 1981; El-Bassel et al. 2004). We can therefore use the latter as an instrument for the former.

\section{Results}

\section{Difference in Wages by Occupations}

In this section, we will begin by considering the raw as well as conditional wage differentials between the two occupations to see if they are significant. While the former can be tested using simple t-tests, the latter will require the Oaxaca-Blinder Method. The raw difference in the earnings of the two groups is 1.272 which suggests that sex workers on average earn 3.57 times what the domestic worker earns per hour (as $e^{1.272}=3.57$ ). Details are presented in table 2 .

(Table 2 here)

Figure 1 plots log of hourly earnings of sex workers and domestic workers from our sample against age. The scatter plot indicates that even without controlling for other covariates the earnings of sex workers are higher than those of domestic workers over all age groups across the sample. The difference is especially stark in the early years of their career and narrows as the workers grow older until it finally disappears when the individuals approach their fifties.

(Figure 1 here)

Turning to the conditional wage differences between these two groups of workers, we present the Oaxaca-Blinder decomposition of the log of hourly earnings in Table 3 . The OB decomposition will allow us to determine the extent of the raw difference that can be explained by the model and the proportion that is left unexplained. Panel A of table 3 reports the mean predictions of the log of earnings according to whether an individual is a sex worker or a domestic worker. Panel B decomposes the difference in log of hourly earnings into three parts. 
The first row reports the differences in endowments which corresponds to the predicted outcomes according to personal characteristics (Jann, 2008). We have a negative value for this. This implies that if the earnings were only explained by individual characteristics, the earnings of domestic workers should have been greater than of sex workers. The second row (titled coefficients) measures the expected change in the domestic workers' mean outcome if the domestic workers had sex workers' coefficients. The third component is the interaction term measuring the simultaneous effect of differences in endowment and coefficient, which in our case is not significant. The fourth and the fifth rows report the explained and unexplained components calculated using the Neumark method (obtaining the reference coefficient from a pooled regression). The explained coefficient is negative, again signifying that if the difference in the earnings could be explained by the coefficients, the earnings of the domestic workers should be greater than the sex workers. The unexplained component constitutes factors that cannot be explained by the individual characteristics. In the case of sex workers and domestic workers these factors may be stigma or vulnerability to abuse or a combination of the two. This exercise gives us an indication that the personal characteristics aren't enough to explain the differences in the earnings in the two groups. However we cannot make any causal claims based on the Oaxaca-Blinder decomposition results as individuals may select into the two groups. We take selection into the trades in the next section.

(Table 3 here)

\section{Stigma in the trade}

As discussed before, we identify stigma in two ways. We first argue that simply being in sex work evokes stigma. This would increase the reservation wage of sex workers. Our first measure of stigma is therefore 'being in sex work'. We first conceptualise stigma as felt stigma which the sex worker experiences as a consequence of simply belonging to the group, which increases the 
reservation price at entry into this trade. The earnings differential met by a sex worker over and above what she would have earned in an otherwise similar trade (in this case domestic work) should provide us with the felt stigma compensation for being in sex work. This we do by estimating 'log of hourly earnings' with 'being sex worker' as the main covariate. Since there may be omitted variables, we use incidents of past violence (violence in the family before joining the trade and violence in the past occupation) as instruments. The results of these models (OLS and IV first and second stage) are presented in columns (1)-(3) in Table 4.

Our second way of identifying stigma is by using the variable 'family_accepts' as denoting stigma. This is a variable constructed from the individual's reporting of how they apprehend stigma from their family. Again there may be omitted variables that affect both the variable 'stigma_family' and log of hourly earnings. We use 'violence in the family before joining the trade' as the instrumental variable in this case. The results of these models are present in columns (4)-(6) in table 4.

(Table 4 here)

The coefficient of the variable 'being sex worker' is approximately 1.54 for both OLS and IV models (columns 1-3 in Table 4) suggesting that being in the stigmatised trade (sex work) results in the individual earning about 4.67 (which is $\mathrm{e}^{1.54}$ ) times more than she would have earned had she been in a similar, but non-stigmatised trade (domestic work). Furthermore, being stigmatised for their work by their family results in an increase in log of hourly earnings of 1.91 which implies that the individual earns 6.7 times what would have been the case otherwise. Both these results together give us confidence in our argument that the sex worker is paid a premium for stigma in the trade.

We will spend a few moments to discuss the validity of the instruments. The endogeneity test for both the IV models gives insignificant results implying that both sex work and stigma_family are 
endogenous. Furthermore, the F-statistic of the first stage is highly significant for both the models taking values of 22.095 and 7.444 indicating that the first stage condition of the instruments is valid. For the model where the endogenous variable is sex work, the over identification tests also give us insignificant results indicating that our instruments are not invalid. There is unfortunately no way to statistically prove the exclusion principle. We believe that the entire impact of past violence on current earnings if through the choice of the stigmatised occupation.

One unobservable factor that may be of concern is the impact of violence on the self-worth of the individual. However, we might expect this impact to be the opposite of the outcome that we see in our results. More specifically, self-worth may be reduced by past violence, and their reduced self-worth may reduce current earnings. This argument would imply that individuals who have faced violence in the past should earn less rather than more, as we see in the case of sex workers. This implies that even if past-violence does have an effect on the individual's current self-worth, and if current self-worth does affect the individual's earning, the effect is probably negligible or the reverse of that in this model.

\section{An alternative explanation}

One alternative explanation in the literature for the sex workers' earnings premium is that since sex work involves risks, the sex workers earn a hazard premium over others. We have argued earlier in the paper that it is difficult to separate the risks from the stigma, as often the risks are a consequence of the stigma. For example, sex workers may be vulnerable to physical, emotional and sexual abuse at work. However, the reason why they are more vulnerable than women in other informal sector work is precisely because women in other trades are more likely to be able to access legal, medical and community help while those in sex work won't. However, one way of separating stigma from risks may be to look at hazard pay within sex work. We can do this by 
looking at whether being abused in the trade has an effect on the earnings of women within sex work. Since we are looking only at the subsample of women who are in sex work, everyone in the sample is by definition stigmatised, and any premium of abuse will be strictly a hazard pay. Once again we use the instruments of past violence (at home before joining the trade and in their past trade) as there may be omitted variables that may affect both being abused in the trade and current hourly earnings.

The results presented in table 5 report the effect that being abused (currently in the trade) has on current earnings for sex workers. Being abused doesn’t have a significant impact. This implies that the hazard pay for vulnerability to abuse isn't significant in our sample. This, together with the significant results for the stigma compensation give us confidence that the market is providing a premium for sex workers for the stigma that is associated with the trade.

(Table 5 here)

\section{Conclusion}

This paper considers the wage differentials earned by sex workers in India using data collected during primary fieldwork in Kolkata and Delhi. We find that sex workers in India earn a premium over domestic workers. We analyse whether this premium relates to the stigma attached to the occupation by using two measures of stigma - that which arises from merely being in the trade and that which arises from the sex worker's perception that her family would not accept her trade. We find that both are significant contributors to the wage differential she earns. We also test (though preliminarily) an alternative explanation of the wage differential where we analyse whether the premium relates to the violence suffered in the trade. We find that this does not have a significant impact on the earnings of the sex worker. We note here that we are only considering general abuse which could be physical, sexual or emotional. The data does not allow us to differentiate between the different forms of violence and hence we are unable to 
see whether a specific form of violence has any effect on the outcomes. We therefore conclude that the main determinant of the wage differential of the sex workers over that of the domestic workers is the stigma attached to sex work, which will increase the reservation price demanded before a woman enters this occupation. Our results contribute to the existing literature on gendered labour markets as they make a comparison of two trades that attract labour of similar socio-economic background and educational attainment. 
Figure 1 Log of hourly Earnings for Sex Workers and Domestic Worker

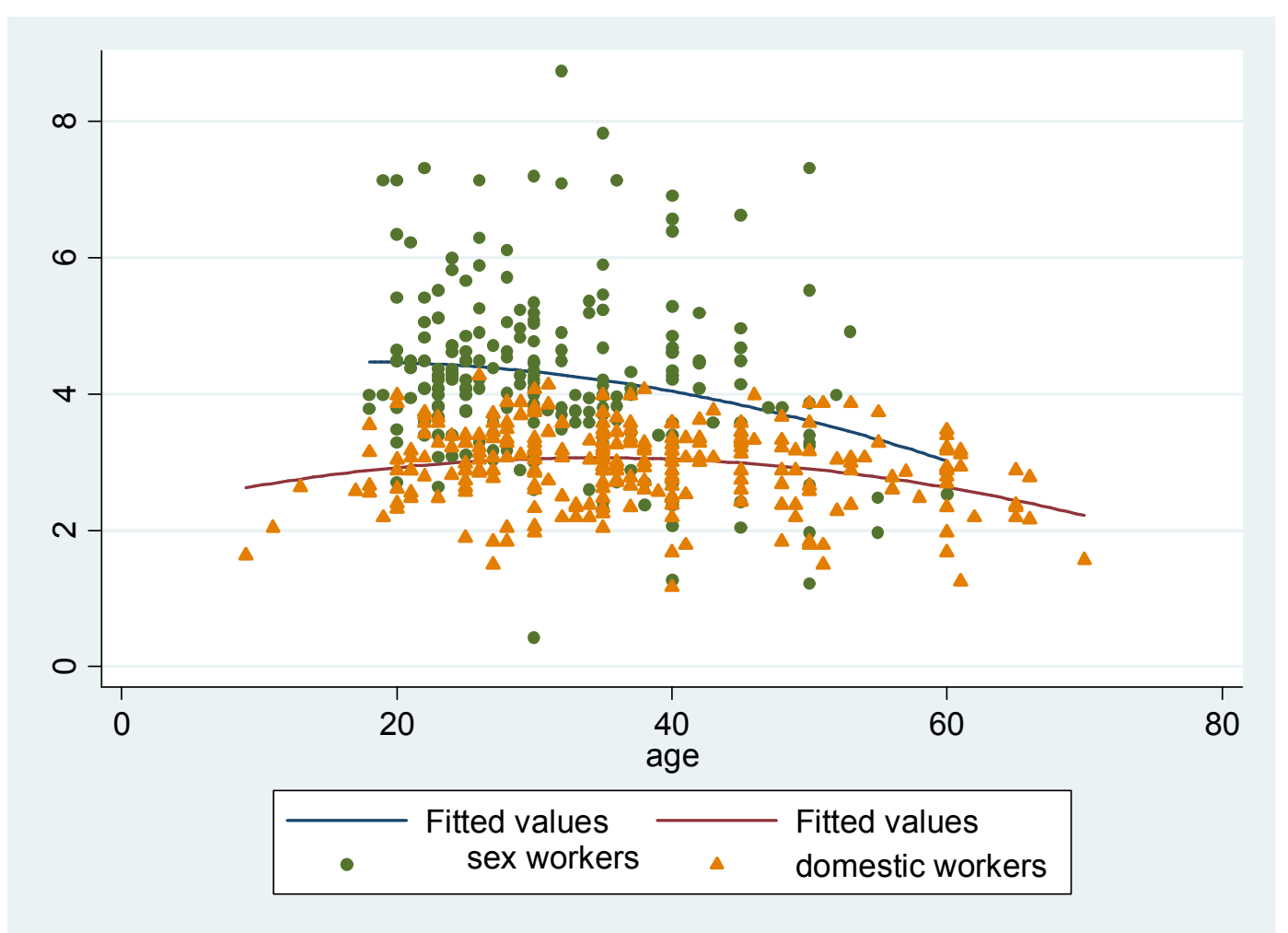

Table 1: Descriptive Statistics for Sex Workers and Domestic Workers

\begin{tabular}{lllll}
\hline & & Domestic & Sex & total \\
& & work & work & \\
\hline Age (mean) & & 37.28 & 32.23 & 34.881 \\
Level of Education & & & & \\
& & & & \\
& No education (\%) & 53.28 & 54.25 & 53.74 \\
& Started primary (\%) & 17.52 & 13.77 & 15.74 \\
& Completed primary (\%) & 13.14 & 8.10 & 10.75 \\
& Started secondary (\%) & 14.23 & 15.38 & 14.78 \\
& Completed secondary (\%) & 1.46 & 5.26 & 3.26 \\
& Higher (\%) & 0.36 & 2.83 & 1.54 \\
& Total observations & 274 & 246 & 520 \\
\hline
\end{tabular}


Marital status

$\begin{array}{llcc}\text { Never married (\%) } & 9.49 & 12.15 & 10.75 \\ \text { Currently with partner (\%) } & 72.26 & 44.53 & 59.12 \\ \text { Total Observation } & 274 & 247 & 521\end{array}$

Religion and Caste

Non-Hindu

(\%)

5.84

27.53

16.12

Hindu

$\mathrm{SC}(\%)$

35.04

28.74

32.05

ST (\%)

2.55

3.64

3.07

OBC (\%)

21.17

10.53

16.12

General (\%)

35.40

29.55

32.63

Total Observations

274

247

521

Family Structure

$\begin{array}{llll}\text { Male headed (\%) } & 74.15 & 75.82 & 74.95 \\ \text { Female headed (\%) } & 25.85 & 24.18 & 25.05 \\ \text { Total observations } & 263 & 244 & 507 \\ \text { Order among siblings (mean) } & 2.50 & 2.60 & 2.54 \\ \text { Number of male siblings (mean) } & 2.01 & 1.83 & 1.93\end{array}$

Number of female siblings (mean)

2.73

2.68

2.71

Asset Ownership of families of individual before joining the trade

\begin{tabular}{llll} 
House (\%) & 40.15 & 43.85 & 41.89 \\
\hline Total Observations & 274 & 244 & 518 \\
\hline Land (\%) & 31.02 & 6.64 & 19.61 \\
\hline Total Observations & 274 & 241 & 515 \\
\hline Jewellery (\%) & 20.15 & 30.74 & 25.15 \\
\hline Total Observations & 273 & 244 & 517
\end{tabular}


Violence faced by the individual before joining the trade

\begin{tabular}{|c|c|c|c|}
\hline Violence in past occupation (\%) & 1.42 & 20.99 & 11.89 \\
\hline Total Observations & 211 & 243 & 454 \\
\hline Violence at home (\%) & 19.34 & 39.34 & 28.76 \\
\hline Total Observations & 274 & 244 & 518 \\
\hline Incidence of violence in the past (\%) & 24.89 & 52.46 & 39.23 \\
\hline Total Observations & 225 & 244 & 469 \\
\hline
\end{tabular}

Family knows and accepts the individual's occupation

$\begin{array}{llll}\text { Yes (\%) } & 93.66 & 25.62 & 61.37 \\ \text { Total Observations } & 268 & 242 & 510\end{array}$

Table 2: Difference in log of hourly Earnings- TTest

\begin{tabular}{lccl}
\hline Group & Obs & Mean & Std. Dev. \\
\hline Sex worker & 225 & 4.228 & 0.068 \\
Domestic worker & 274 & 2.956 & 0.035 \\
combined & 499 & 3.530 & 0.047 \\
Difference & & 1.272 & 0.072 \\
Degrees of & 497 & & \\
freedom & & & \\
t-stat & -15.216 & & \\
\hline H0: diff $=0$; Ha: $\operatorname{diff}<0, \operatorname{Pr}(\mathrm{T}<\mathrm{t})=0.000$ &
\end{tabular}

Table 3: Decomposition of 'log of hourly earnings' for sex workers and domestic workers

VARIABLES Sex worker




\begin{tabular}{ll}
\hline Panel A: Differential & \\
\hline Prediction 1 & $4.228 * * *$ \\
& $(0.0827)$ \\
Prediction 2 & $2.959 * * *$ \\
& $(0.0356)$ \\
Difference & $1.269 * * *$ \\
& $(0.0901)$
\end{tabular}

\section{Panel B: Decomposition}

\begin{tabular}{ll}
\hline Endowments & $-0.151^{* *}$ \\
Coefficients & $(0.0584)$ \\
& $1.482^{* * *}$ \\
Interaction & $(0.124)$ \\
& -0.0619 \\
& $(0.118)$ \\
\hline Explained & $(0.0829)$ \\
\hline Unexplained & $-0.255^{* * *}$ \\
& $(0.072)$ \\
& $1.525^{* * *}$ \\
\hline Observations & $(0.092)$ \\
\hline
\end{tabular}

Oaxaca Blinder decomposition. Covariates used: Age, Square of Age, Level of education, Hindu upper caste, Family member in their industry, Not a migrant, Location= delhi, Hours worked. * $\mathrm{p}<0.1, * * \mathrm{p}<0.05, * * * \mathrm{p}<0.01$. Standard errors presented in parenthesis. 
Table 4: Estimation of Log of hourly earnings for pooled sample of sex workers and domestic workers

\begin{tabular}{|c|c|c|c|c|c|c|}
\hline & (1) & (2) & (3) & (4) & (5) & (6) \\
\hline & OLS & first & second & OLS & first & second \\
\hline \multirow[t]{2}{*}{ sex work } & $1.535 * * *$ & & $1.541 * * *$ & & & \\
\hline & $(0.0834)$ & & $(0.297)$ & & & \\
\hline \multirow[t]{2}{*}{ stigma_family } & & & & $0.856^{* * *}$ & & $1.910 * *$ \\
\hline & & & & $(0.0955)$ & & $(0.840)$ \\
\hline \multirow[t]{2}{*}{ age } & 0.0152 & -0.0136 & 0.00164 & 0.0168 & -0.00582 & 0.0238 \\
\hline & $(0.0171)$ & $(0.00973)$ & $(0.0196)$ & $(0.0210)$ & $(0.0101)$ & $(0.0239)$ \\
\hline \multirow[t]{2}{*}{ square of age } & -0.00033 & 0.00049 & -0.000197 & -0.000432 & -0.0003 & -0.000410 \\
\hline & $(0.00022)$ & $(0.000121)$ & $(0.000239)$ & $(0.000265)$ & $(0.000128)$ & $(0.000294)$ \\
\hline \multirow[t]{2}{*}{ level of education } & 0.0431 & -0.0155 & 0.0322 & 0.0551 & 0.00200 & 0.0516 \\
\hline & $(0.0279)$ & $(0.0150)$ & $(0.0297)$ & $(0.0340)$ & $(0.0164)$ & $(0.0377)$ \\
\hline \multirow[t]{2}{*}{ high caste hindu } & 0.0357 & $-0.0727 *$ & 0.0266 & -0.0203 & -0.0570 & 0.0395 \\
\hline & $(0.0748)$ & $(0.0396)$ & $(0.0810)$ & $(0.0910)$ & $(0.0439)$ & $(0.111)$ \\
\hline \multirow[t]{2}{*}{ family in the industry } & 0.0132 & $-0.280 * * *$ & 0.0768 & $-0.239 * *$ & $-0.267 * * *$ & 0.0406 \\
\hline & $(0.0769)$ & $(0.0403)$ & $(0.119)$ & $(0.0927)$ & $(0.0431)$ & $(0.244)$ \\
\hline \multirow[t]{2}{*}{ local (not a migrant) } & $0.136^{*}$ & $-0.152 * * *$ & 0.126 & 0.00278 & $-0.130 * * *$ & 0.143 \\
\hline & $(0.0744)$ & $(0.0394)$ & $(0.0930)$ & $(0.0901)$ & $(0.0431)$ & $(0.149)$ \\
\hline \multirow[t]{2}{*}{ Location: Delhi } & $0.615 * * *$ & 0.0125 & $0.697 * * *$ & $0.402 * * *$ & -0.00290 & $0.418 * * *$ \\
\hline & $(0.0775)$ & $(0.0436)$ & $(0.0856)$ & $(0.0937)$ & $(0.0454)$ & $(0.104)$ \\
\hline hours worked & $-0.021 * * *$ & $0.00298 * * *$ & $-0.022 * * *$ & $0.0191 * * *$ & $0.00310 * * *$ & $-0.023 * * *$ \\
\hline
\end{tabular}




\begin{tabular}{|c|c|c|c|c|c|c|}
\hline \multicolumn{6}{|c|}{ Journal of Development Studies } & \multirow{2}{*}{$\begin{array}{r}\text { Page } 28 \\
(0.00334)\end{array}$} \\
\hline & $(0.00140)$ & $(0.000774)$ & $(0.00186)$ & $(0.00172)$ & $(0.000818)$ & \\
\hline grew up in male headed & -0.0113 & $0.0831 * *$ & -0.0431 & 0.0928 & 0.0106 & 0.0771 \\
\hline nuclear family & $(0.0701)$ & $(0.0379)$ & $(0.0794)$ & $(0.0856)$ & $(0.0414)$ & $(0.0956)$ \\
\hline Growing up family & 0.0584 & 0.0728 & 0.0365 & 0.125 & $0.0837 *$ & 0.0408 \\
\hline owned house & $(0.0796)$ & $(0.0444)$ & $(0.0909)$ & $(0.0980)$ & $(0.0472)$ & $(0.127)$ \\
\hline Growing up family & 0.0860 & $-0.349 * * *$ & 0.0859 & $-0.284 * *$ & $-0.237 * * *$ & -0.0234 \\
\hline owned land & $(0.0969)$ & $(0.0532)$ & $(0.155)$ & $(0.116)$ & $(0.0550)$ & $(0.243)$ \\
\hline Growing up family & 0.0475 & $0.124 * * *$ & 0.0557 & $0.298 * * *$ & -0.0680 & $0.371 * * *$ \\
\hline owned jewellery & $(0.0861)$ & $(0.0461)$ & $(0.0949)$ & $(0.105)$ & $(0.0506)$ & $(0.130)$ \\
\hline \multicolumn{7}{|l|}{ Instruments } \\
\hline Faced violence at home & & $0.160 * * *$ & & & $0.120 * * *$ & \\
\hline before joining trade & & $(0.0401)$ & & & $(0.0439)$ & \\
\hline Faced occupation in last & & $0.298 * * *$ & & & & \\
\hline occupation & & $(0.0576)$ & & & & \\
\hline \multirow[t]{2}{*}{ Constant } & $3.189 * * *$ & $0.898 * * *$ & $3.550 * * *$ & $3.699 * * *$ & $0.650 * * *$ & $2.965 * * *$ \\
\hline & $(0.361)$ & $(0.201)$ & $(0.488)$ & $(0.441)$ & $(0.211)$ & $(0.758)$ \\
\hline Observations & 485 & 428 & 428 & 476 & 476 & 476 \\
\hline R-squared & 0.602 & 0.477 & 0.606 & 0.419 & 0.265 & 0.266 \\
\hline First stage test & & & & 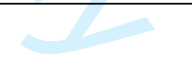 & & \\
\hline F-statistic & & $22.095^{* * *}$ & & & $7.444 * * *$ & \\
\hline \multicolumn{7}{|l|}{ endogeniety test } \\
\hline Durban Score & & & 0.0277 & & & 2.01976 \\
\hline
\end{tabular}

First stage test

\begin{tabular}{|c|c|c|c|c|c|}
\hline & Jou & nal of Develop & ent Studies & & \\
\hline & $(0.00140)$ & $(0.000774)$ & $(0.00186)$ & $(0.00172)$ & $(0.000818$ \\
\hline grew up in male headed & -0.0113 & $0.0831 * *$ & -0.0431 & 0.0928 & 0.0106 \\
\hline nuclear family & $(0.0701)$ & $(0.0379)$ & $(0.0794)$ & $(0.0856)$ & $(0.0414)$ \\
\hline Growing up family & 0.0584 & 0.0728 & 0.0365 & 0.125 & $0.0837 *$ \\
\hline owned house & $(0.0796)$ & $(0.0444)$ & $(0.0909)$ & $(0.0980)$ & $(0.0472)$ \\
\hline Growing up family & 0.0860 & $-0.349 * * *$ & 0.0859 & $-0.284 * *$ & $-0.237 * *$ \\
\hline owned land & $(0.0969)$ & $(0.0532)$ & $(0.155)$ & $(0.116)$ & $(0.0550)$ \\
\hline Growing up family & 0.0475 & $0.124 * * *$ & 0.0557 & $0.298 * * *$ & -0.0680 \\
\hline owned jewellery & $(0.0861)$ & $(0.0461)$ & $(0.0949)$ & $(0.105)$ & $(0.0506)$ \\
\hline Instruments & & & & & \\
\hline Faced violence at home & & $0.160 * * *$ & & & $0.120 * * *$ \\
\hline before joining trade & & $(0.0401)$ & & & $(0.0439)$ \\
\hline Faced occupation in last & & $0.298 * * *$ & & & \\
\hline occupation & & $(0.0576)$ & & & \\
\hline Constant & $3.189 * * *$ & $0.898 * * *$ & $3.550 * * *$ & $3.699 * * *$ & $0.650 * * *$ \\
\hline & $(0.361)$ & $(0.201)$ & $(0.488)$ & $(0.441)$ & $(0.211)$ \\
\hline Observations & 485 & 428 & 428 & 476 & 476 \\
\hline R-squared & 0.602 & 0.477 & 0.606 & 0.419 & 0.265 \\
\hline First stage test & & & & 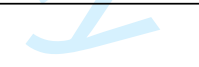 & \\
\hline F-statistic & & $22.095 * * *$ & & & $7.444 * * *$ \\
\hline endogeniety test & & & & & \\
\hline Durban Score & & & 0.0277 & & \\
\hline
\end{tabular}

endogeniety test

2.01976

$\mathrm{p}$ value

0.8677

0.1553

Wu-Hausman

0.0267

0.1617

$\mathrm{p}$ value

0.8701

0.1617 


\begin{tabular}{lc}
\hline Over-identification test & \\
\hline Sargam score & 0.5095 \\
p value & 0.4753 \\
Basmann Score & 0.4922 \\
p value & 0.4829 \\
& \\
\hline $\mathrm{p}<0.1, * * \mathrm{p}<0.05, * * * \mathrm{p}<0.001$. Standard errors presented in parenthesis
\end{tabular}

Table 5: Estimation for log of hourly earnings for subsample of sex workers only

\begin{tabular}{llll}
\hline & $(1)$ & $(2)$ & $(3)$ \\
\hline & OLS & first & second \\
\hline Abuse in trade & 0.0242 & & -0.0185 \\
& $(0.129)$ & & $(0.515)$ \\
age & $0.0850^{*}$ & $-0.0608^{* *}$ & 0.0825 \\
square of age & $(0.0492)$ & $(0.0256)$ & $(0.0557)$ \\
level of education & $-0.00170^{* *}$ & $0.000973 * * *$ & $-0.00166^{* *}$ \\
& $(0.000697)$ & $(0.000361)$ & $(0.000821)$ \\
Location: Delhi & 0.0210 & $-0.0466^{*}$ & 0.0191 \\
high caste hindu & $(0.0472)$ & $(0.0246)$ & $(0.0510)$ \\
family in the industry & 0.144 & 0.0815 & 0.148 \\
& $(0.137)$ & $(0.0720)$ & $(0.140)$ \\
& $0.295^{*}$ & 0.128 & $0.300^{*}$
\end{tabular}




$\begin{array}{llll} & (0.144) & (0.0758) & (0.140) \\ \text { hours worked } & -0.0255^{* * *} & -4.60 \mathrm{e}-05 & -0.0255^{* * *} \\ & (0.00234) & (0.00124) & (0.00228) \\ \text { grew up in male headed nuclear family } & -0.0105 & -0.0682 & -0.0134 \\ \text { Growing up family owned house } & (0.131) & (0.0690) & (0.131) \\ & 0.0753 & 0.195 * * & 0.0833 \\ \text { Growing up family owned land } & (0.158) & (0.0829) & (0.179) \\ \text { Growing up family owned jewellery } & 0.176 & -0.0820 & 0.172 \\ & (0.256) & (0.135) & (0.253) \\ & 0.0805 & -0.175 * & 0.0726 \\ & (0.177) & (0.0944) & (0.195)\end{array}$

\section{Instruments}

Faced violence at home before joining trade

$0.229^{* * *}$

Faced occupation in last occupation

Constant

Observations

R-squared

First stage test

F-statistic

$4.112 * * *$

$(0.867)$

220

0.508

0.159
$4.167 * * *$

(1.059)

220

0.507

endogeniety test

Durban Score

0.0073

p-value

0.9319 
Overidentification test

\begin{tabular}{lc}
\hline Sargam score & 0.1303 \\
p-value & 0.7181 \\
Basmann Score & 0.1215 \\
p-value & 0.7274
\end{tabular}

$* \mathrm{p}<0.1, * * \mathrm{p}<0.05, * * * \mathrm{p}<0.01$. Standard errors presented in parenthesis.

i Durbar is the largest collective of sex workers with membership of 65000 sex workers from West Bengal, India. Information regarding their work can be found at http://durbar.org/

ii In Kolkata the sex worker participants worked and resided in four red-light areas in South Kolkata- Kalighat, Chetla, Khiddirpur and Rambagan and in three red-light areas in North Kolkata- Rabindra Sarani, Set Bagan and Sonagachhi. Officials of Durbar further put us in contact with a sex workers collective in Delhi named Savera who helped identifty sex workers in Rohini district which is a suburb in West Delhi and GB Road which is located in Eastcentral Delhi.

iii The research method and questionnaire were approved by ethical committees at the University of Reading and Durbar to ensure that questions were not intrusive to the privacy or safety of the respondents and also that no sex worker under the age of 18 was recruited for the study. The researcher had proposed a reimbursement of Rs 50 for the participant's time. However, Durbar, the organisation that provided primary contact for the study were strongly opposed to the idea of providing monitory incentives to women who were recruited through their contact. One program officer had argued in a meeting with the researcher that providing monitory incentives would build expectations of being rewarded for participation in any other studies that the sex workers may be required to participate in, and locally funded smaller studies (including studies carried out by Durbar) will often not have the funding to meet such expectations. Consequently the sex worker participants were not paid for participation while the domestic worker participants were. The interviews were carried out by the researcher and three research assistants (one male and two female) in Bengali and Hindi. While all efforts were made to ensure that the participant was alone during the time of the interview, it was often not possible. Where the participants were interviewed at their residence, in all cases the homes were a small one roomed space with multiple members of the family living together and in such cases it was often not possible to ask other family members to leave the premise. Often, in the case of sex work, two women resided together in such one room spaces with one sex worker acting as the madam/pimp for the other. In such cases two of the interviewers would simultaneously engage the two women, one inside the house/room and one outside so that the responses would not be influenced by the presence of the 
other sex worker. Consent was acquired at the beginning of each interview and the respondents were assured that they could stop at any point of the interview.

iv Live-out domestic workers are workers who do not reside at the homes of their employers

v Source: Mukherjee and Mukherjee (2007) for estimate on sex work and International Labour Organisation (2013) for estimate on domestic work.

vi Scheduled Castes (SC), Scheduled Tribes (ST) and Other Backward Classes (OBC) are official categorisation of groups that have been historically discriminated against because of their caste or tribal background in India. The Constitution of India recognises these groups as socio-economically deprived and endeavours to positively discriminate in their favour in their favour in educational institutions, government jobs, and seats in legislative assembly.

vii Because of sensitive nature of past violence, we were not able to gather enough information on the exact type of abuse, and when the abuse occurred. There were concerns that detailed questions on types of past violence may have psychological effects on the respondents that were beyond the scope of this study, and could potentially derail the conversation from the focused questionnaire. We can thus only look at the effect of having faced violence at some point after joining the trade on the earnings of the individual.

viii As robustness check we estimated an alternative model where we included the category 'neutral' to the 'agree' categories. That is, we constructed the variable 'stigma_family' to take value 0 if the individual's response to the question was 'neutral', 'agree' and 'strongly agree' and 1 otherwise. The resulting values of the estimation were similar to those presented in Table 4 in sign and significance and slightly larger in magnitude.

${ }^{i x}$ We additionally ran the models discussed below on subset of women who had a previous occupation (i.e. were not unemployed before joining their current trade). The results aren't categorically different and have similar magnitude and significance as those presented here. These results can be made available on request. 


\section{Reference}

Alonzo, Angelo A and Nancy R Reynolds (1995) “Stigma, HIV and AIDS: An Exploration and Elaboration of Stigma Trajectory" Social Science and Medicine, 41(3), 305-315

Arunachalam, R., \& Shah, M. (2008). Prostitutes and brides?. The American Economic Review, 98, 516-522.

Ashforth, Blake E and Glen E Kreiner (1999) “How Can You Do It?”: Dirty Work and the Challenge of Constructing a Positive Identity Academy of Management review, 24, 413-434

Ashforth, Blake E and Glen E Kreiner (2014) "Dirty Work and Dirtier Work: Difference in Countering Physical, Social and Moral Stigma Management and Organisational Review, 10, pages $81-2014$

Atkinson, R., \& Flint, J. (2001). Accessing hidden and hard-to-reach populations: Snowball research strategies. Social research update, 33(1), 1-4

Basu, Ishika, Smarajit Jana, Mary Jane Rotheram-Borus, Dallas Swendeman, Sung-Jae Lee, Peter Newman, and Robert Weiss. (2004). "HIV prevention among sex workers in India." Journal of acquired immune deficiency syndromes 36, 845-852

Blanchard, J. F., O’Neil, J., Ramesh, B. M., Bhattacharjee, P., Orchard, T., \& Moses, S. (2005). Understanding the social and cultural contexts of female sex workers in Karnataka, India: implications for prevention of HIV infection. The Journal of infectious diseases, 191(Supplement_1), S139-S146.

Blinder, A. S. (1973). Wage discrimination: reduced form and structural estimates. Journal of Human resources, 436-455. 
Boels, D., \& Verhage, A. (2016). Prostitution in the neighbourhood: Impact on residents and implications for municipal regulation. International Journal of Law, Crime and Justice, 46, 43-56.

Brents, Barbara G., and Kathryn Hausbeck(2005) "Violence and Legalized Brothel Prostitution in Nevada Examining Safety, Risk, and Prostitution Policy. " Journal of Interpersonal Violence 20, 270-295.

Campani, G. (2000). Immigrant women in Southern Europe: social exclusion, domestic work and prostitution in Italy, Macmillan, London.

Cameron, A. C., \& Trivedi, P. K. (2005). Microeconometrics: methods and applications. Cambridge university press. Cambridge

Deering, K. N., Amin, A., Shoveller, J., Nesbitt, A., Garcia-Moreno, C., Duff, P., Argento, E \& Shannon, K. (2014). A systematic review of the correlates of violence against sex workers. American journal of public health, 104, 42-54.

Della Giusta, M., Di Tommaso, M. L., \& Strøm, S. (2009). Who is watching? The market for prostitution services. Journal of Population Economics, 22, 501-516.

Della Giusta, M., Di Tommaso, M., \& Strøm, S. (2008). Sex markets: A denied industry. Routledge. London and New York

Economic and Political Weekly Editorial (2014) “The World's Oldest Debate: The Debate For and Against Legalisation of Sex Work Must Get More Attention” Economic and Political Weekly, 49(47), 8-94

Edlund, L., \& Korn, E. (2002). A theory of prostitution. Journal of political Economy, 110, $181-214$ 
Ehrenreich, B., \& Hochschild, A. R. (2003). Global women. Nannies, Maids, and Sex Workers in the New Economy. Granta Books. London

El-Bassel, N., Witte, S. S., Wada, T., Gilbert, L., \& Wallace, J. (2001). Correlates of partner violence among female street-based sex workers: substance abuse, history of childhood abuse, and HIV risks. AIDS patient care and STDs, 15(1), 41-51.

Frank, O., \& Snijders, T. (1994). Estimating the size of hidden populations using snowball sampling. Journal of Official Statistics, 10, 53-67.

Gerassi, L., Edmond, T., \& Nichols, A. (2016). Design strategies from sexual exploitation and sex work studies among women and girls: Methodological considerations in a hidden and vulnerable population. Action Research, 15, 161-176.

Gertler, P., Shah, M., \& Bertozzi, S. M. (2005). Risky business: the market for unprotected commercial sex. Journal of political Economy, 113, 518-550.

Goffman, Erving. (2009) Stigma: Notes on the management of spoiled identity. Simon and Schuster. New York, London, Toronto

Goodman, L. A. (1961). Snowball sampling. The annals of mathematical statistics, 32, 148170.

Grassi, E., \& Di Cintio, M. (2012). Uncertainty, flexible labour relations and R\&D expenditure. Metroeconomica, 68, 91-120

Groger, L., Mayberry, P. S., \& Straker, J. K. (1999). What we didn't learn because of who would not talk to us. Qualitative Health Research, 9, 829-835.

Halli, S. S., Ramesh, B. M., O'Neil, J., Moses, S., \& Blanchard, J. F. (2006). The role of collectives in STI and HIV/AIDS prevention among female sex workers in Karnataka, India. AIDS care, 18, 739-749. 
Hamid, A. (2006). Harsh, Everyday Realities. Economic and Political Weekly, 41(13), 12351237.

Huang, Shirlena, and Brenda SA Yeoh (2007). "Emotional labour and transnational domestic work: the moving geographies of 'maid abuse'in Singapore."Mobilities 2, 195-217

Huang, Yingying, Gail E. Henderson, Suiming Pan, and Myron S. Cohen (2004). "HIV/AIDS risk among brothel-based female sex workers in China: assessing the terms, content, and knowledge of sex work." Sexually transmitted diseases 31, 695-700.

Hussmanns, Ralf (2004). Defining and measuring informal employment. Bureau of Statistics Paper, ILO, Geneva, February (http://www.

ilo.org/public/english/bureau/stat/download/papers/meas. pdf).

Hussmanns, Ralf (2005) Measuring the informal economy: From employment in the informal sector to informal employment Working Paper No. 53, International Labour Organisation, Geneva

International Labour Office (2013) Domestic workers across the world: Global and regional statistics and the extent of legal protection. Geneva: International Labour Office.

Jacobsson, Nikolas \& Andreas Kotsadan (2011) 'Gender Equity and Prostitution: An Investigation of Attitudes in Norway and Sweden' Feminist Economics, 17, 31-58.

Jameela, Nalini (2009). Autobiography of a Sex Worker. Translated by J. Devika.: Westland Books Pvt. Ltd Chennai, India

Jann, B. (2008). The Blinder-Oaxaca decomposition for linear regression models. The Stata Journal, 8, 453-479.

Kanbur, Ravi (2005). Conceptualising Informality: Regulation and Enforcement Discussion Paper No. 4186, IZA, Bonn 
Kleinman, Arthur, and Rachel Hall-Clifford(2009). "Stigma: a social, cultural and moral process." Journal of Epidemiology and Community Health, 63, 418-419.

Kramer, L. A. (2004). Emotional experiences of performing prostitution. Journal of Trauma Practice, 2, 186-197.

Kramer, Lisa A., and Ellen C. Berg. "A survival analysis of timing of entry into prostitution: The differential impact of race, educational level, and childhood/adolescent risk factors." Sociological Inquiry, 73,511-528.

Lazarus, L., Deering, K. N., Nabess, R., Gibson, K., Tyndall, M. W., \& Shannon, K. (2012). Occupational stigma as a primary barrier to health care for street-based sex workers in Canada. Culture, health \& sexuality, 14, 139-150.

Link, Bruce G and Jo C Phelan (2001) “Conceptualizing Stigma' Annual Review of Sociology, 27, 363-385

Mukherji, K. K., and S. Muherjee (2007) "Girls and women in prostitution in India."Department of Women and Child Development, New Delhi, India Murty, O. P. (2009) "Maid abuse." Journal of forensic and legal medicine, 16, 290-296.

Niang, Cheikh Ibrahima, Placide Tapsoba, Ellen Weiss, Moustapha Diagne, Youssoupha Niang, Amadou Mody Moreau, Dominique Gomis, Abdoulaye Sidbé Wade, Karim Seck, and Chris Castle(2003). "'It's raining stones': stigma, violence and HIV vulnerability among men who have sex with men in Dakar, Senegal." Culture, Health \& Sexuality, 5, 499-512.

Noy, C. (2008). Sampling knowledge: The hermeneutics of snowball sampling in qualitative research. International Journal of social research methodology, 11, 327-344.

Oaxaca, R. (1973). Male-female wage differentials in urban labor markets. International economic review, 14, 693-709. 
Raghuram, P. (2001). Caste and gender in the organisation of paid domestic work in India. Work, Employment and Society, 15, 607-617.

Rao, V., Gupta, I., Lokshin, M., \& Jana, S. (2003). Sex workers and the cost of safe sex: the compensating differential for condom use among Calcutta prostitutes. Journal of Development Economics, 71, 585-603.

Saggurti, Niranjan, Ravi K. Verma, Shiva S. Halli, Suvakanta N. Swain, Rajendra Singh, Hanimi Reddy Modugu, Saumya Ramarao, Bidhubhusan Mahapatra, and Anrudh K. Jain (2011). "Motivations for entry into sex work and HIV risk among mobile female sex workers in India." Journal of biosocial science 43,535-554.

Sahni, R., \& Shankar, V. K. (2011). The first pan-India survey of sex workers: A Summary of preliminary findings. Center for Advocacy on Stigma and Marginalisation (CASAM). Accessed November $23^{\text {rd }}, 2018$ https://www.sangram.org/resources/Pan_India_Survey_of_Sex_workers.pdf Sallman, J (2010). “Living with Stigma: Women's Experience of Prostitution and Substance Use" Affilia: Journal of Women and Social Work 25, 146-159

Sanders, Teela (2004). "A continuum of risk? The management of health, physical and emotional risks by female sex workers." Sociology of health \& illness 26, 557-574.

Sarkar, Kamalesh, Baishali Bal, Rita Mukherjee, Sekhar Chakraborty, Suman Saha, Arundhuti Ghosh, and Scott Parsons (2008). "Sex-trafficking, violence, negotiating skill, and HIV infection in brothel-based sex workers of eastern India, adjoining Nepal, Bhutan, and Bangladesh." Journal of health, population, and nutrition, 26(2), 223-231.

Scambler, Graham (2007). "Sex Work Stigma: Opportunist Migrants in London” Sociology, 14, 1079-1096. 
Sen, Samita and Nilanjana Sengupta (2012). "Marriage, Work and Education among Domestic Workers in Kolkata" Economic and Political Weekly. 47(43) Review of Women's Studies. $67-77$

Sharma, Sonal \& Eesha Kunduri (2015). “Of Law, Language and Labour: Situating the Need for Legislation in Domestic Work" Economic and Political Weekly, 50(28), web exclusive. Accessed November 29 ${ }^{\text {th }}, 2018$ https://www.epw.in/journal/2015/28/web-exclusives/lawlanguage-and-labour.html

Sopheab, H., P. M. Gorbach, S. Gloyd, and Hor Bun Leng.(2003). "Rural sex work in Cambodia: work characteristics, risk behaviours, HIV, and syphilis." Sexually transmitted infections. 79(4), 335-335.

StataCorp (2013) Stata Statistical Software: Release 13. College Station, TX: StataCorp LP Vasanthi, N. (2011). Addressing paid domestic work: A public policy concern. Economic and Political Weekly, 46(43), 85-93.

Wadhawan, Neha (2013). "Living in Domesti-city: Women and Migration for Domestic Work from Jharkhand" Economic and Political Weekly, 48(43), 47-54

Wilson, Erin C., Robert Garofalo, Robert D. Harris, Amy Herrick, Miguel Martinez, Jaime Martinez, Marvin Belzer, Transgender Advisory Committee, and Adolescent Medicine Trials Network for HIV/AIDS Interventions. (2009)."Transgender female youth and sex work: HIV risk and a comparison of life factors related to engagement in sex work." AIDS and Behavior, 13, 902-913.

Wong, W. C., Holroyd, E., \& Bingham, A. (2011). Stigma and sex work from the perspective of female sex workers in Hong Kong. Sociology of health \& illness, 33, 50-6. 